Article

\title{
Field Measurements of Water Supply and Drainage Noise in the Bathrooms of Korea's Multi-Residential Buildings
}

\author{
Hong-Seok Yang ${ }^{1}$, Hyun-Min Cho ${ }^{2}$ and Myung-Jun Kim ${ }^{2, *}$ \\ 1 Land and Housing Institute, Korea Land and Housing Corporation, Daejeon 34047, Korea; \\ acousticsyang@gmail.com \\ 2 School of Architecture, University of Seoul, Seoul 02504, Korea; chunryou@nate.com \\ * Correspondence: mjunkim@uos.ac.kr; Tel.: +82-2-6490-2761 \\ Academic Editor: Jian Kang \\ Received: 7 October 2016; Accepted: 15 November 2016; Published: 22 November 2016
}

\begin{abstract}
In Korea, water supply and drainage noises result in one of the main noise complaints because more than $50 \%$ of people reside in multi-residential buildings. In this study, a series of field measurements were therefore carried out to examine the current noise situation. The noise levels were measured in the bathrooms of the upper and lower floors, as well as in habitable rooms. The measurement results for the bathrooms of the lower floor $(N=113)$ are $47.8 \mathrm{dBA}$ (water closet), $42.7 \mathrm{dBA}$ (basin), and $33.9 \mathrm{dBA}$ (bathtub) for water drainage, while values vary between $33.7 \mathrm{dBA}$ and $37.0 \mathrm{dBA}$ for the water supply. The results suggest that the water drainage noise needs to be controlled first. The system bathroom ( $42.8 \mathrm{dBA})$ produced lower noise levels than the wet construction method (48.2 dBA) for all of the sanitary wares. The highest noise levels in the living rooms $(N=11)$ and bedrooms $(N=8)$ of the lower floor are $34.3 \mathrm{dBA}$ and $39.1 \mathrm{dBA}$, respectively. The average noise level in the rooms $(N=19)$ is $37.8 \mathrm{dBA}$. The overall result suggests that it is necessary to develop an acoustic guideline to satisfy the higher Class of the 2nd ISO/CD 19488, although the current noise level satisfies Class C (living room) and Class D (bedroom).
\end{abstract}

Keywords: water supply and drainage noise; bathroom; multi-residential building; field measurement

\section{Introduction}

Due to their high expectations for the quality of their housing, the residents of multi-residential buildings demand regulations regarding the levels of indoor noise such as floor impact noise, airborne noise through walls, and water supply and drainage noises. Especially in Korea, the level of this requirement is higher than those of other countries because more than $50 \%$ of people reside in multi-residential buildings with high property prices. The Korean government has consequently enacted several noise regulations regarding the allowable indoor noise level and classifications for floor impact noise, the sound insulation of walls, and transport noise.

In contrast to the above noise regulations, water supply and drainage noises from bathrooms are evaluated by a Korean certification tool named G-SEED (Green Standard for Energy and Environmental Design) [1], which assigns different points for each tier in the evaluation of the sustainability of a building. In G-SEED, the sustainability of the water supply and drainage noises is mainly determined by whether pipes and construction methods that result in the generation of low noise levels have been applied or not, rather than the noise level.

The noise generated from sanitary wares such as a water closet is unpleasant for residents living on lower floors. In Korea, water supply and drainage noises result in one of the main noise complaints because the drain-pipe system is installed through the penetration of a slab between the upper and 
lower floors in most multi-residential buildings. The penetrated vertical pipe is then connected to horizontal pipes that are installed above the ceiling. The pipe system draining the fluctuating fluid consequently comprises a vulnerable structure that transmits sound energy with structure-borne and airborne paths [2-5].

In Korea, multi-residential buildings have been built with various floor plans. Generally, the number of bathrooms is one for floor plans with two bedrooms or fewer, while more than two are built for floor plans with more than three bedrooms. In housing units with more than two bathrooms, one bathroom is generally attached to a master bedroom. The water supply and drainage noises can therefore be transmitted easily through an adjacent bedroom, which causes noise annoyances during rest periods, as well as sleep disturbances at night.

In this study, a series of field measurements was therefore carried out to investigate the current situation regarding water supply and drainage noises in terms of the bathrooms and adjacent rooms of 14 types of floor plans for multi-residential buildings in Korea. This measurement campaign was conducted as a preliminary study for the proposal of an acoustic-design guideline so that a certain noise level can be satisfied for the water supply and drainage in the bathrooms and adjacent rooms of multi-residential buildings.

\section{Literature Review on Noise Criteria and Regulations}

\subsection{Korea}

In Korea, national regulations and recommendations for indoor noise levels with respect to water supply and drainage noises in multi-residential buildings are currently absent, although a KS (Korean Standard) [6,7] that is related to the method for measurement and evaluation has been issued. On the other hand, national regulations on acceptable indoor noise levels are implemented for floor impact noise and airborne noise from neighbors [8,9]. The minimum requirement for the indoor noise level from external traffic noise is also managed by a relevant national regulation [10]. As described in Table 1, the regulations for the indoor noise level in $\mathrm{L}_{\mathrm{eq}}$ (equivalent continuous A-weighted sound-pressure level) during the daytime ranges between $43 \mathrm{dBA}$ and $45 \mathrm{dBA}$, while the $5 \mathrm{dBA}$ for night-time is stricter. Impulsive noise such as floor-impact noise is regulated at less than $57 \mathrm{dBA}$ in $\mathrm{L}_{\max }$ (maximum A-weighted sound-pressure level) during the daytime.

Table 1. Korean regulation on acceptable indoor noise level for different noise sources.

\begin{tabular}{cccc}
\hline \multirow{2}{*}{ Type of Noise Sources } & & \multicolumn{2}{c}{ Indoor Noise Level (dBA) } \\
\cline { 3 - 4 } & Noise Index & $\begin{array}{c}\text { Daytime } \\
\text { (06:00 to 22:00) }\end{array}$ & $\begin{array}{c}\text { Night-Time } \\
\text { (22:00 to 06:00) }\end{array}$ \\
\hline Structure-borne noise (e.g., floor-impact noise) & & 43 & 38 \\
Airborne noise (e.g., TV noise from neighbor) & $\mathrm{L}_{\mathrm{eq}}$ & 57 & 52 \\
Road traffic noise & $\mathrm{L}_{\mathrm{eq}}$ & 45 & 40 \\
Water supply and drainage noise & $\mathrm{L}_{\mathrm{eq}}$ & \multicolumn{3}{c}{ None } \\
\hline
\end{tabular}

The G-SEED is a Korean certification system that was created to accomplish the construction of environmental-friendly buildings. Within G-SEED, the measures for the reduction of water supply and drainage noises are assessed according to four tiers, as described in Table 2. The tier in Table 2 is determined by checking whether building elements and construction methods that generate low noise levels have been applied or not. The highest point is four, and is given to the construction method called "in-floor type", whereby the pipes on the slab are installed at the same floor.

In Korea, the field measurements of water supply and drainage noises are carried out based on KS F 2870 (supply noise) and KS F 2871 (drainage noise). The standards describe factors such as the location and height of microphones, room conditions, and background-noise correction. Alternatively, KS F 2872 [11] is the rating method for water supply noise based on the NC-curve and A-weighted SPL (sound-pressure level). 
Table 2. Criteria and credits in G-SEED for measures to reduce water supply and drainage noises.

\begin{tabular}{ccc}
\hline Tier & Criteria & Weighting Factors \\
\hline 1 & 9 points or above & 1.0 \\
2 & 7 to 8 points & 0.75 \\
3 & 5 to 6 points & 0.5 \\
4 & 4 points and below & 0.25 \\
- Dwelling-water-supply pressure less than $2.5 \mathrm{kgf} / \mathrm{cm}^{2}: 3$ points \\
- Low-flow toilet less than 6 L, single-flush (or 9 L/5 L, dual-flush): 2 points \\
- Installation of buffer at pipe-crossing slabs: 1 point \\
- Low-noise drainage pipe: 2 points \\
- In-floor type for water supply and drainage pipes: 4 points \\
- Noise-reduction measure for air ducts: 2 points \\
\hline
\end{tabular}

\subsection{ISO and ASHRAE}

Recently, researchers involved with the ISO/TC 43/SC 2/WG 29 proposed the 2nd ISO/CD 19488 [12] titled "Acoustic classification of dwellings". The ISO standard is a guideline to facilitate the national implementation of the acoustic classification scheme for residential buildings. The classification scheme specifies the criteria in habitable rooms in dwellings from indoor service equipment producing intermittent noise or irregular noise such as water supply and drainage noises from neighboring spaces, with the six classes described in Table 3. The specified classes are related to in situ measurements, either in the frequency bands in accordance with ISO 16032 [13], or directly in the A-weighted maximum F SPL in accordance with ISO 10052 [14]. The lowest class is F, indicating that the minimum limit is less than $46 \mathrm{dBA}$ in habitable rooms.

Table 3. Class limits for service equipment noise from neighboring spaces (The 2nd ISO/CD 19488).

\begin{tabular}{|c|c|c|c|c|c|c|c|}
\hline Type of Space and Sources & Quantity & Class A & Class B & Class C & Class D & Class E & Class $\mathbf{F}$ \\
\hline $\begin{array}{l}\text { In habitable rooms in dwellings from } \\
\text { service equipment, producing } \\
\text { intermittent or irregular noise from } \\
\text { neighboring spaces }\end{array}$ & $\mathrm{L}_{\mathrm{AF}, \max , \mathrm{nT}}$ & $\leq 26$ & $\leq 30$ & $\leq 34$ & $\leq 38$ & $\leq 42$ & $\leq 46$ \\
\hline
\end{tabular}

The ASHRAE (American Society of Heating, Refrigerating, and Air-Conditioning Engineers, Piscataway, NJ, USA) also suggests a recommended A-weighted SPL as a slow response for various transient plumbing-noise sources in residential buildings, as described in Table 4 [15]. It is evident that the acceptable noise level in the bathroom is less than $45 \mathrm{dBA}$, while the threshold is $35 \mathrm{dBA}$ in rooms.

Table 4. Recommended maximum A-weighted SPL for various transient plumbing-noise sources in buildings (ASHRAE handbook).

\begin{tabular}{cc}
\hline Receiving Room & $\mathbf{L}_{\text {Amax }}$ (Slow Response) (dB) \\
\hline Residential bedroom, living room, dining room & 35 \\
Residential bathroom, kitchen & 45 \\
\hline
\end{tabular}

\section{Methodology}

\subsection{Description of the Studied Housing Units}

Field measurements of the water supply and drainage noises from the bathroom were carried out in 14 types of housing units with different floor areas and plans. The floor areas considered in this study are $33 \mathrm{~m}^{2}, 36 \mathrm{~m}^{2}, 46 \mathrm{~m}^{2}, 59 \mathrm{~m}^{2}, 74 \mathrm{~m}^{2}$, and $84 \mathrm{~m}^{2}$, and they represent the area for exclusive use. Different floor plans with the same floor area were also selected to examine the characteristics of the 
sound propagation from the bathroom to the adjacent room. The type of housing unit is distinguished by a symbol that indicates the floor area with a number and a plan in an upper-case letter (e.g., $59 \mathrm{~A}=\mathrm{A}$ type of $59 \mathrm{~m}^{2}$ ). The number of bathrooms in the housing units with a small floor area between $33 \mathrm{~m}^{2}$ and $46 \mathrm{~m}^{2}$ is one, while the housing units with a large floor area between $59 \mathrm{~m}^{2}$ and $84 \mathrm{~m}^{2}$ contain two bathrooms that are attached to the living room and bedroom. Figure 1 shows the 14 floor plans of the studied housing units with different floor areas.

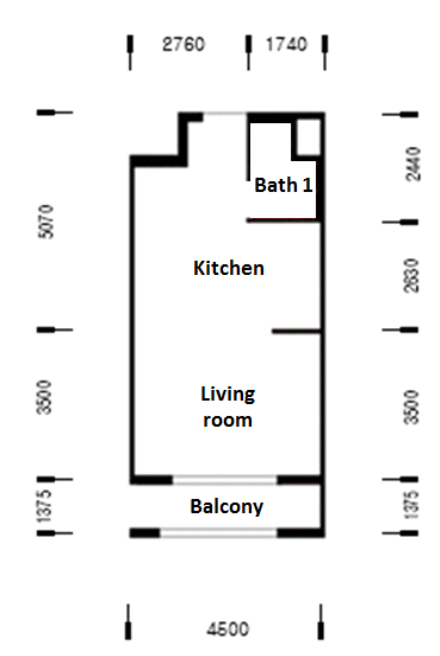

(a)

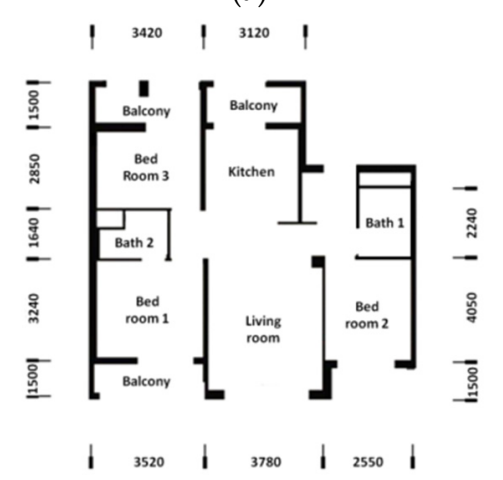

(d)

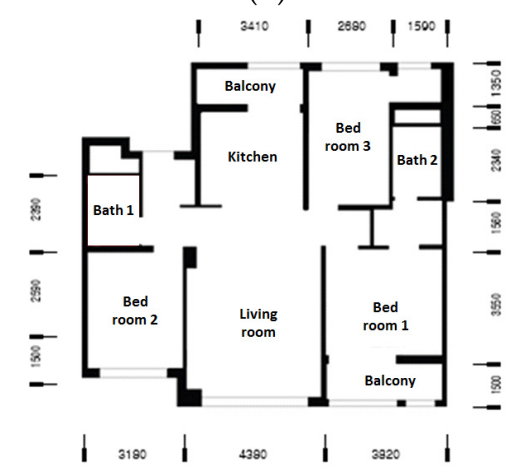

(g)

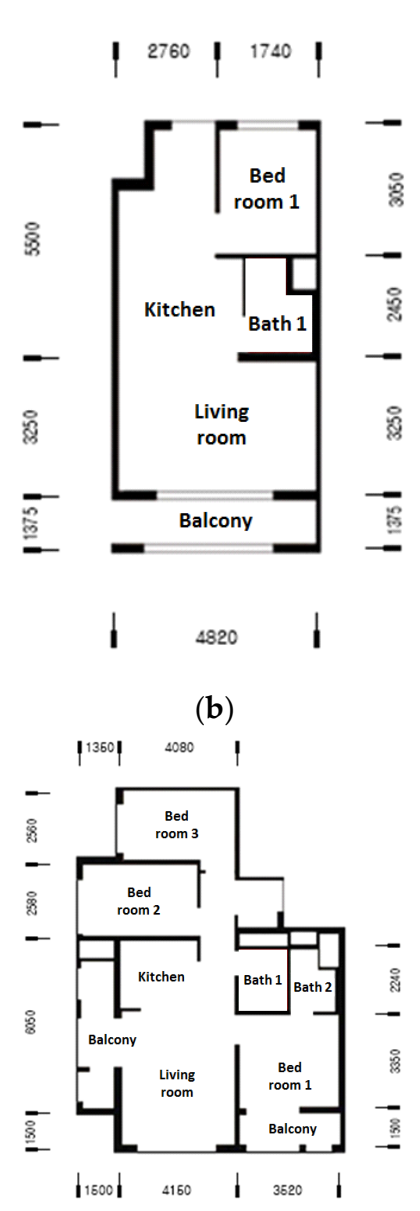

(e)

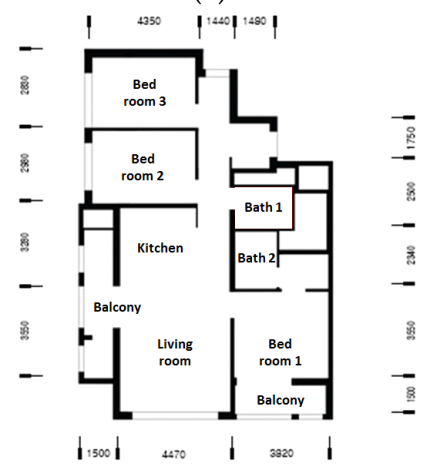

(h)

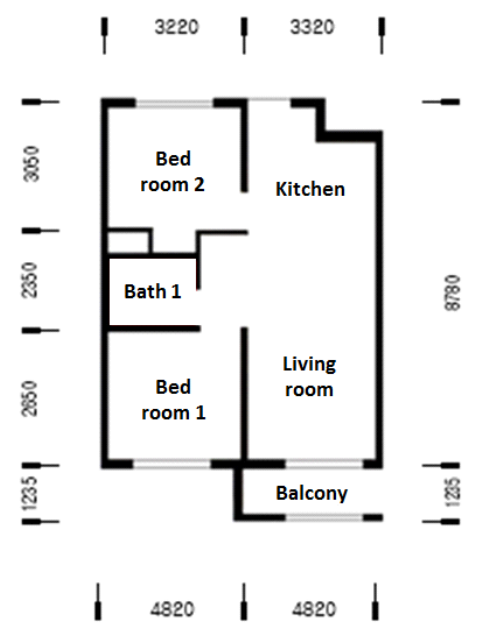

(c)

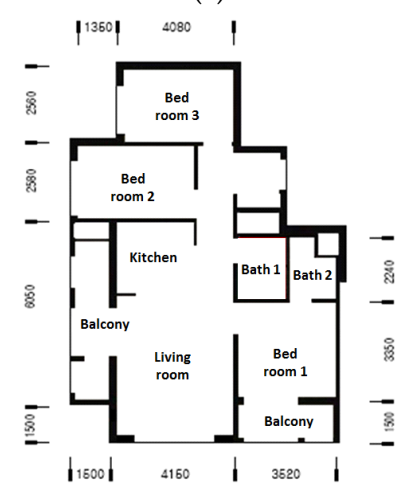

(f)

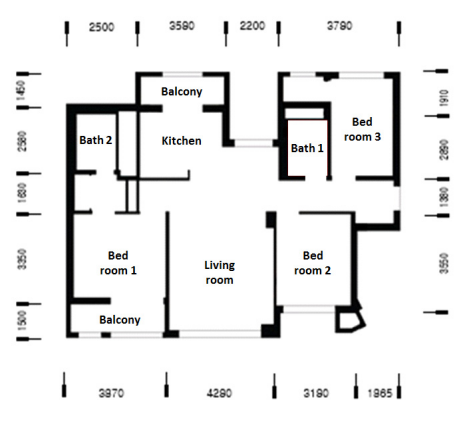

(i)

Figure 1. Cont. 


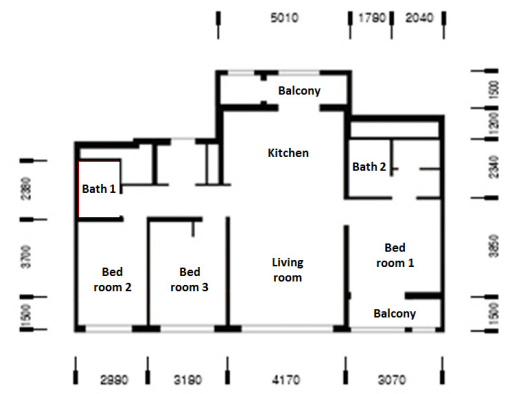

(j)

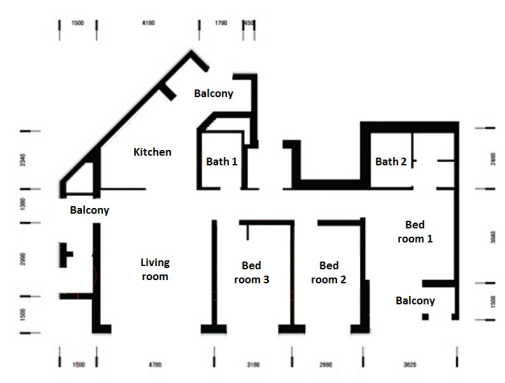

$(\mathbf{m})$

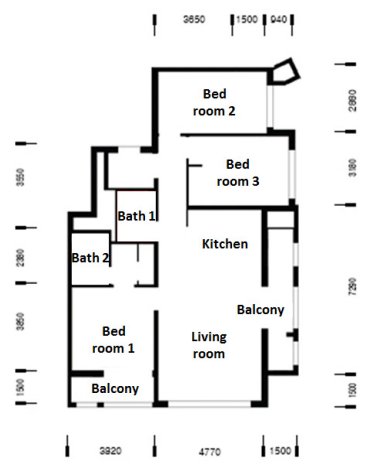

$(\mathbf{k})$

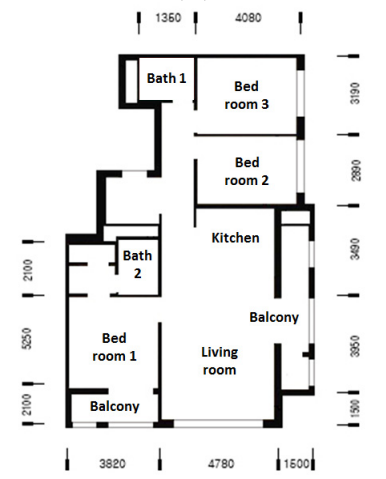

(n)

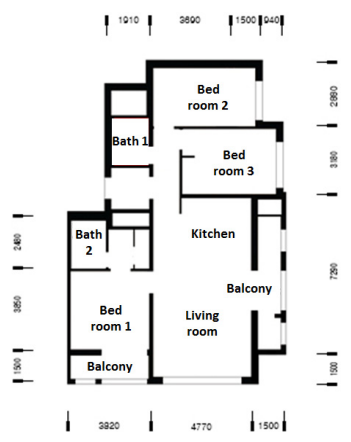

(1)

Figure 1. The 14 floor plans of the studied housing units with different floor areas: (a) 33 type; (b) 36 type; (c) 46 type; (d) 59A type; (e) 59B type; (f) 59C type; (g) 74A type; (h) 74B type; (i) 74C type; (j) 84A type; (k) 84B1 type; (l) $84 \mathrm{~B} 3$ type; (m) 84C type; (n) $84 \mathrm{D}$ type.

For each type of housing unit, the measurements were also conducted on different floors to examine the fluctuation in noise level due to the altitude of the bathroom in multi-residential buildings with a maximum of 28 floors. The floor in the multi-residential buildings was selected by including the ground, middle, and top floors. Although it depends on the total floors of a multi-residential building, the number of selected properties is between four and six units with a step of the fifth floor. Table 5 lists the numbers of bathrooms and properties that were measured in the buildings. As described in Table 5, the total number of the studied housings where the noise level in the bathroom of the lower floor was measured according to the use of sanitary wares including the water closet, basin, and bath is 64 (113 bathrooms). Additional measurements for the noise level in 11 properties (19 bathrooms) with different floor plans were also carried out on the middle floor of the building, as follows: (1) noise level in the bathroom of the upper floor; and (2) noise level in the adjacent living room and bedroom of the lower floor. Table 6 summarizes the locations for the noise level measurements.

Although the 2nd ISO/CD 19488 suggests a normalization of the RT in the noise level, the RT measurements for the living room and bedroom are omitted here to examine the current situation in situ, which is the method suggested in the Korean standard. It is expected, however, that the influence of the RT in the normalizing of the noise level is approximately from $2.6 \mathrm{~dB}$ to $5.8 \mathrm{~dB}$, based on the previous work that shows that the RT in the unoccupied rooms is between $0.9 \mathrm{~s}$ and $1.9 \mathrm{~s}$ at $500 \mathrm{~Hz}$ [16]. 
Table 5. The number of lower-floor bathrooms $(N=113)$ and properties $(N=64)$ studied.

\begin{tabular}{|c|c|c|c|}
\hline $\begin{array}{c}\text { Type of } \\
\text { Housing Unit }\end{array}$ & $\begin{array}{l}\text { No. of Bathrooms } \\
\text { (A) }\end{array}$ & $\begin{array}{l}\text { No. of Properties with the } \\
\text { Receiving Bathroom (B) }\end{array}$ & $\begin{array}{c}\text { No. of Studied } \\
\text { Bathrooms }(A \times B)\end{array}$ \\
\hline 33 & 1 & 5 (1st, 5th, 13th, 16th, 19th floors) & 5 \\
\hline 36 & 1 & 5 (1st, 6th, 13th, 20th, 27th floors) & 5 \\
\hline 46 & 1 & 5 (1st, 6th, 13th, 20th, 27th floors) & 5 \\
\hline $59 \mathrm{~A}$ & 2 & 5 (3rd, 6th, 10th, 15th, 20th) & 10 \\
\hline $59 \mathrm{~B}$ & 2 & 5 (3rd, 6th, 10th, 15th, 19th) & 10 \\
\hline $59 C$ & 2 & 5 (3rd, 6th, 10th, 15th, 20th) & 10 \\
\hline $74 \mathrm{~A}$ & 2 & 4 (1st, 5th, 10th, 14 floors) & 8 \\
\hline $74 \mathrm{~B}$ & 2 & 5 (1st, 5th, 10th, 15th, 19th floors) & 10 \\
\hline $74 \mathrm{C}$ & 2 & 4 (1st, 5th, 15th, 19th floors) & 8 \\
\hline $84 \mathrm{~A}$ & 2 & 3 (10th, 15th, 19th floors) & 6 \\
\hline 84B1 & 2 & 4 (1st, 5th, 10th, 14th floors) & 8 \\
\hline 84B3 & 2 & 4 (1st, 5th, 15th, 19th floors) & 8 \\
\hline $84 \mathrm{C}$ & 2 & 5 (1st, 5th, 16th, 19th, 24th floors) & 10 \\
\hline $84 \mathrm{D}$ & 2 & 5 (3rd, 6th, 12th, 17th, 25th) & 10 \\
\hline
\end{tabular}

* The bold number of floors indicates the floor where additional noise level measurements were conducted as a representative case for each floor plan (11 floor plans except for 74C, 84B3, and 84C).

Table 6. Measured location and number of properties for each measurement parameter.

\begin{tabular}{ccc}
\hline Measurement Parameter & \multicolumn{1}{c}{ Location } & No. of Properties \\
\hline \multirow{3}{*}{ Noise level } & In the bathroom of the lower floor & 64 properties (113 bathrooms) \\
\cline { 2 - 3 } & $\begin{array}{c}\text { In the bathroom of the upper floor } \\
\end{array}$ & $\begin{array}{c}\text { In the adjacent living room and } \\
\text { bedroom of the lower floor }\end{array}$ \\
\hline
\end{tabular}

\subsection{Description of the Studied Bathrooms}

In this study, the measurements were conducted for the bathrooms for which the UBR (unit bathroom) system and wet construction method have been applied. The UBR system is the prefabricated bathroom for which preassembled elements such as finishes, sanitary wares, concealed pipes, conduits, ceiling, bathroom cabinets, and a shower screen are installed. The UBR system is installed in consideration of the advantages in terms of time- and human power-saving, waterproofing, and soundproofing. In spite of the advantages of the UBR system, most multi-residential buildings in Korea have bathrooms using the wet construction method due to the feasibility of the interior design and the high level of impact noise on lightweight walls from the UBR system. Among the studied housing units with 14 different floor plans, the UBR system had been installed in three of the housing units with small floor areas between $33 \mathrm{~m}^{2}$ and $46 \mathrm{~m}^{2}$, while 11 housing units with relatively large floor areas above $59 \mathrm{~m}^{2}$ had been built using the wet construction method. As given in Table 7, the width (W) and depth (D) of the bathrooms are from $2110 \mathrm{~mm}$ to $2500 \mathrm{~mm}$ and $1600 \mathrm{~mm}$ to $1790 \mathrm{~mm}$, respectively, indicating similar sizes, although the floor areas are different. The heights (D) are different according to the construction methods: $2080 \mathrm{~mm}$ for the UPR system and $2270 \mathrm{~mm}$ for the wet construction method.

Figure $2 \mathrm{a}, \mathrm{b}$ show the cross-sections of the bathrooms for which the UBR system and wet construction method were applied, respectively. It can be seen that the thickness of the floor slab is $150 \mathrm{~mm}$ for both construction methods. The thicknesses of the air cavity between the slab and the ceiling are $455 \mathrm{~mm}$ and $255 \mathrm{~mm}$ for the UBR system and the wet construction method, respectively. The ceilings of both construction methods are covered by $2.5 \mathrm{~mm}$ PVC (polyvinyl chloride) panels without acoustic absorbers, and they hang on lightweight steel frames. The nominal diameter of the PVC pipes connected to the water closet is $100 \mathrm{~mm}$, with a weight of $1737 \mathrm{~g} / \mathrm{m}$ and a thickness of $3.1 \mathrm{~mm}$. PVC pipes with a $50 \mathrm{~mm}$ nominal diameter are used to drain water from the basin and bathtub. The vertical and horizontal pipes for the water closet were connected with 90-degree elbows that are 
designed to generate low noise levels. The tilting angle of the horizontal pipe is 5 degrees. The water supply pressure is less than $2.5 \mathrm{kgf} / \mathrm{m}^{2}$. The water closet installed in the housing units is a siphon type containing a six-liter water cistern. As shown in Figure 2b, the floors of the bathrooms for which the wet construction method was applied have multiple layers consisting of floor tiles, cement mortar, thermal insulator, and waterproofing. The wall of the bathroom facing the living room and bedroom was built with $190 \mathrm{~mm}$ thick masonry.

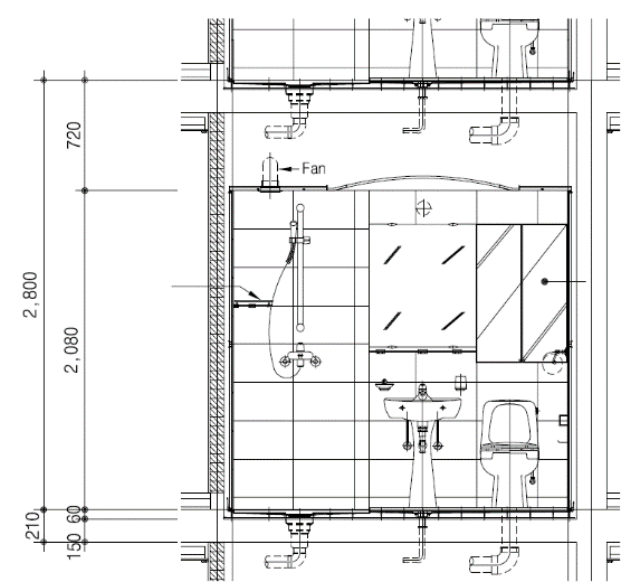

(a)

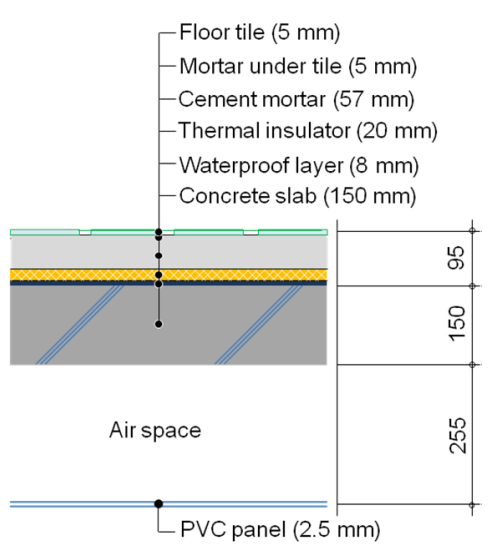

(b)

Figure 2. Cross-sections of bathrooms for which the (a) UBR system and (b) wet construction method had been applied.

Table 7. Dimensions and construction methods for the bathrooms in each housing unit.

\begin{tabular}{|c|c|c|c|}
\hline \multirow{2}{*}{$\begin{array}{c}\text { Type of } \\
\text { Housing Unit }\end{array}$} & \multicolumn{2}{|c|}{ Dimension of the Bathroom $(\mathrm{W} \times \mathrm{D} \times \mathrm{H}(\mathrm{mm}))$} & \multirow[b]{2}{*}{ Construction Method } \\
\hline & $\begin{array}{l}\text { Bathroom Attached to the } \\
\text { Living Room }\end{array}$ & $\begin{array}{c}\text { Bathroom Attached to } \\
\text { the Bedroom }\end{array}$ & \\
\hline 33 & $2440 \times 1740 \times 2080\left(3.11 \mathrm{~m}^{2}\right)$ & - & UBR system \\
\hline 36 & $2380 \times 1740 \times 2080\left(3.06 \mathrm{~m}^{2}\right)$ & - & \\
\hline 46 & $2110 \times 1710 \times 2080\left(3.61 \mathrm{~m}^{2}\right)$ & - & \\
\hline $59 \mathrm{~A}$ & $2240 \times 1790 \times 2270\left(3.62 \mathrm{~m}^{2}\right)$ & $2290 \times 1640 \times 2270\left(3.02 \mathrm{~m}^{2}\right)$ & Wet construction \\
\hline $59 \mathrm{~B}$ & $2240 \times 1790 \times 2270\left(3.88 \mathrm{~m}^{2}\right)$ & $2240 \times 1640 \times 2270\left(3.07 \mathrm{~m}^{2}\right)$ & \\
\hline $59 \mathrm{C}$ & $2240 \times 1790 \times 2270\left(3.89 \mathrm{~m}^{2}\right)$ & $2480 \times 1730 \times 2270\left(3.00 \mathrm{~m}^{2}\right)$ & \\
\hline $74 \mathrm{~A}$ & $2340 \times 1790 \times 2270\left(3.95 \mathrm{~m}^{2}\right)$ & $2340 \times 1600 \times 2270\left(3.56 \mathrm{~m}^{2}\right)$ & \\
\hline $74 \mathrm{~B}$ & $2340 \times 1790 \times 2270\left(3.79 \mathrm{~m}^{2}\right)$ & $2230 \times 1790 \times 2270\left(3.83 \mathrm{~m}^{2}\right)$ & \\
\hline $74 \mathrm{C}$ & $2390 \times 1740 \times 2270\left(4.00 \mathrm{~m}^{2}\right)$ & $2340 \times 1600 \times 2270\left(3.58 \mathrm{~m}^{2}\right)$ & \\
\hline $84 \mathrm{~A}$ & $2420 \times 1790 \times 2270\left(3.80 \mathrm{~m}^{2}\right)$ & $2390 \times 1740 \times 2270\left(3.99 \mathrm{~m}^{2}\right)$ & \\
\hline 84B1 & $2420 \times 1600 \times 2270\left(3.87 \mathrm{~m}^{2}\right)$ & $2500 \times 1620 \times 2270\left(4.06 \mathrm{~m}^{2}\right)$ & \\
\hline $84 \mathrm{~B} 3$ & $2340 \times 1590 \times 2270\left(3.73 \mathrm{~m}^{2}\right)$ & $2430 \times 1650 \times 2270\left(4.01 \mathrm{~m}^{2}\right)$ & \\
\hline $84 \mathrm{C}$ & $2180 \times 1740 \times 2270\left(3.79 \mathrm{~m}^{2}\right)$ & $2340 \times 1620 \times 2270\left(3.80 \mathrm{~m}^{2}\right)$ & \\
\hline $84 \mathrm{D}$ & $2340 \times 1790 \times 2270\left(3.72 \mathrm{~m}^{2}\right)$ & $2340 \times 1790 \times 2270\left(4.05 \mathrm{~m}^{2}\right)$ & \\
\hline
\end{tabular}

\subsection{Experimental Setup}

The noise levels for the water supply and drainage were measured in the bathroom and adjacent room of the multi-residential buildings. The equipment used for the measurement included a four-channel Harmonie system $(0.1 \mathrm{~dB})$ with $\frac{1}{2}$ " microphone (G.R.A.S. Type $\left.40 \mathrm{AF}\right)$ and preamplifiers (G.R.A.S. Type 26AG), and the NA-28 portable sound level meter (RION). In the adjacent room including the bedroom and living room, the four-channel Harmonie system and one NA-28 were located at a height of $1.2 \mathrm{~m}$. Four microphones were set up at the corner positions $0.75 \mathrm{~m}$ from the room surfaces. One microphone was placed at the center of the room. The noise level in the room was the average value measured over the five microphones. No furniture or other obstacles were in the room. The noise levels in the upper and lower bathrooms were measured using one NA-28 simultaneously 
located at the center position of each bathroom with a height of $1.2 \mathrm{~m}$. One NA-28 was also located $1 \mathrm{~m}$ from the door. In total, eight microphones were used simultaneously for the noise-level measurements for 11 housings with different floor plans, while only one NA-28 was installed in the bathroom of the lower floor for the remaining properties $(N=53)$. Figure 3 shows the experimental setup for the measurements in the bathroom and adjacent rooms of the lower floor. The views of the experimental setups in the bathroom and living room are also shown in Figure 4.

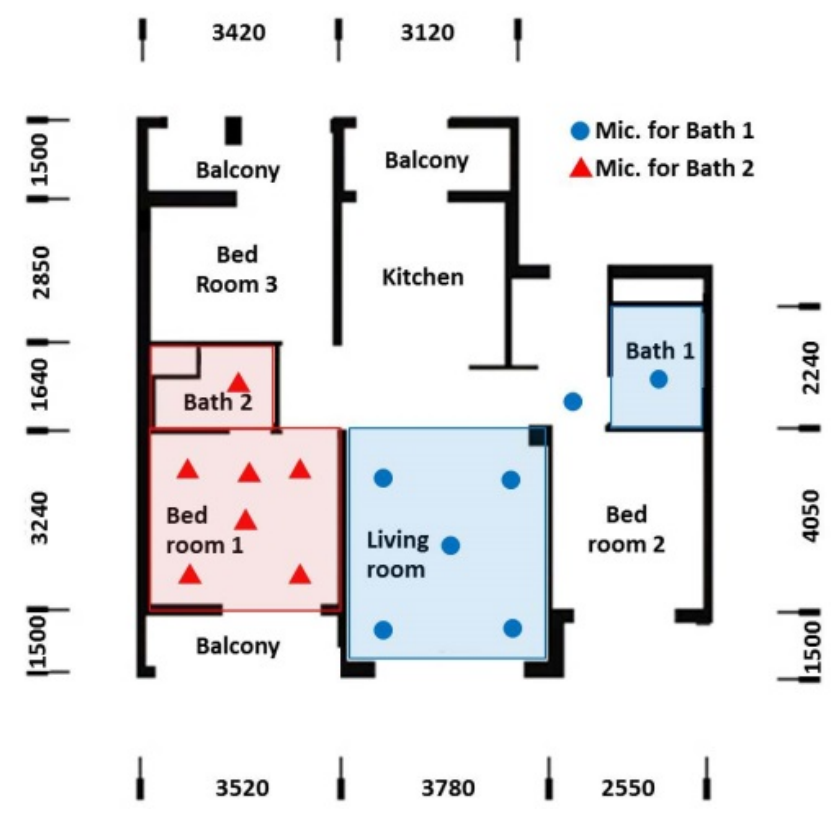

Figure 3. Illustration of the experimental setup for the measurement in the bathroom and adjacent rooms of the lower floor (59A type).

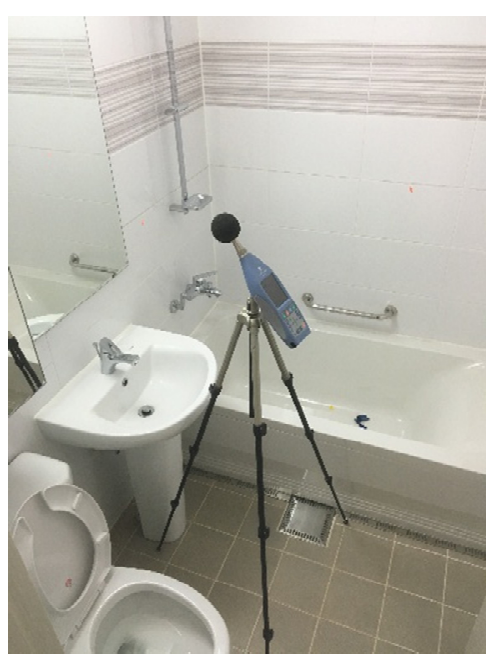

(a)

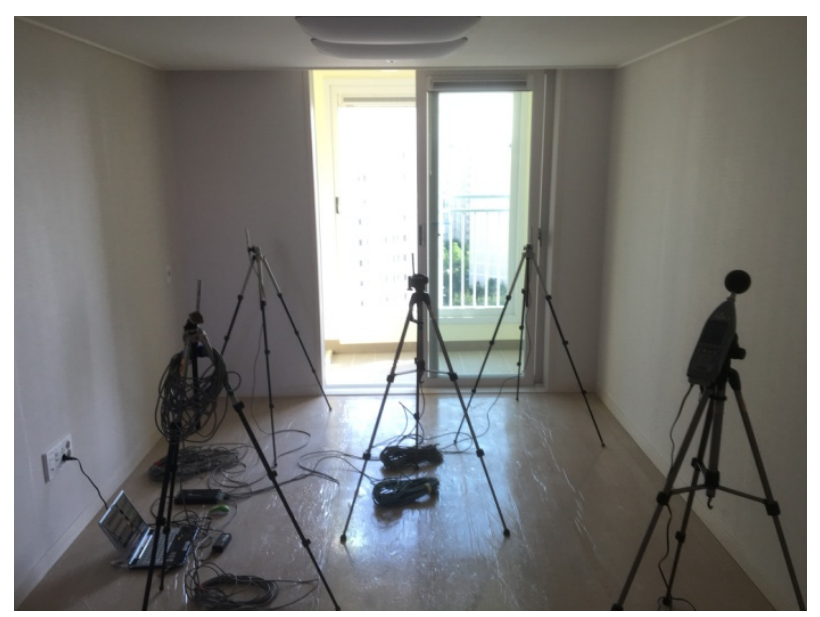

(b)

Figure 4. Views of the experimental setups in (a) the bathroom and (b) the living room.

The water supply and drainage noises were generated by three consecutive operations of each sanitary ware including the water closet, basin, and bathtub. After the bathtub and basin were filled full of water, the water was drained through the pipe.

The background noises in the bathroom and adjacent rooms are below $25 \mathrm{dBA}$ for the measurements at night-time. This leads to a high $\mathrm{S} / \mathrm{N}$ (signal-to-noise) ratio over $10 \mathrm{dBA}$, indicating an insignificant influence of the background noise on the measurement results. 
The noise level was measured in $\mathrm{L}_{\mathrm{AFmax}}$, as recommended in the 2nd ISO/CD 19488, and in consideration of the fluctuating characteristics of the water supply and drainage noises. The RT in the adjacent rooms was not normalized to examine the noise level in situ.

\section{Results}

\subsection{Time History of Water Supply and Drainage Noises}

The use of the sanitary wares in the bathroom of the upper floors generates water supply and drainage noises in the bathroom and adjacent room of the lower floors through structure-borne and airborne transmissions. The time history of the noise generated by the use of each sanitary ware comprises the different characteristics of operation time and fluctuation due to the difference of the amount of used water, the flow velocity, and the diameter and shape of the pipe, among others. In the bathroom, the main sanitary wares include the water closet, basin, and bathtub. Figure 5 shows the time history of the water supply and drainage noises that were measured in different locations simultaneously including in the bathrooms of the upper and lower floors, in front of a closed door, and in the adjacent living room. The time history of the noise from the use of the water closet shows that the water drainage noise generates the peak level during the operation time for about $7 \mathrm{~s}$ from the initial usage. After the drainage, water is supplied to the cistern with a low fluctuation of the noise level for approximately $32 \mathrm{~s}$. In all of the measurement locations, the water drainage noise generates the peak noise level due to a siphon, indicating that the maximum noise level is mainly determined during the water drainage. The water supply and drainage noises from the use of the basin and bathtub also generate continuous noise during the water supply, while the noise fluctuates during the water drainage. The difference between the noise levels of the bathrooms of the upper and lower floors is approximately $40 \mathrm{dBA}$.

Figure 6 shows the time history of the water supply and drainage noises from the use of the water closets installed in 19 bathrooms of 11 housings with different floor plans (11 bathrooms attached to the living room, and eight bathrooms attached to the bedroom). Here, the shortest operation time of the water supply and drainage is approximately $28 \mathrm{~s}$ for the bathroom attached to the bedroom of the $84 \mathrm{~A}$ type, while it is approximately $47 \mathrm{~s}$ for the bathroom attached to the living room of the 59A type.

\subsection{Noise Level in the Bathroom}

The water supply and drainage noises were measured in the bathrooms of the upper $(N=19)$ and lower $(N=113)$ floors according to the use of the sanitary wares including the water closet, basin, and bathtub. Figure 7 shows an example of the frequency spectrum in one octave band for the water supply and drainage noises measured in the bathrooms of the upper and lower floors for the 59A type. The frequency spectrum was analyzed for the noise level measured in $\mathrm{L}_{\mathrm{AFmax}}$ during the operation time of each sanitary ware. The results show that the use of the water closet generates a relatively high noise level in the bathrooms of the upper and lower floors compared to the basin and bathtub. Generally, the three sanitary wares produced strong sound energies at middle and high frequencies above $500 \mathrm{~Hz}$ in the bathroom. It is expected that the high noise levels at the middle and high frequencies cause more sensitive subjective responses due to the use of the sanitary wares. 


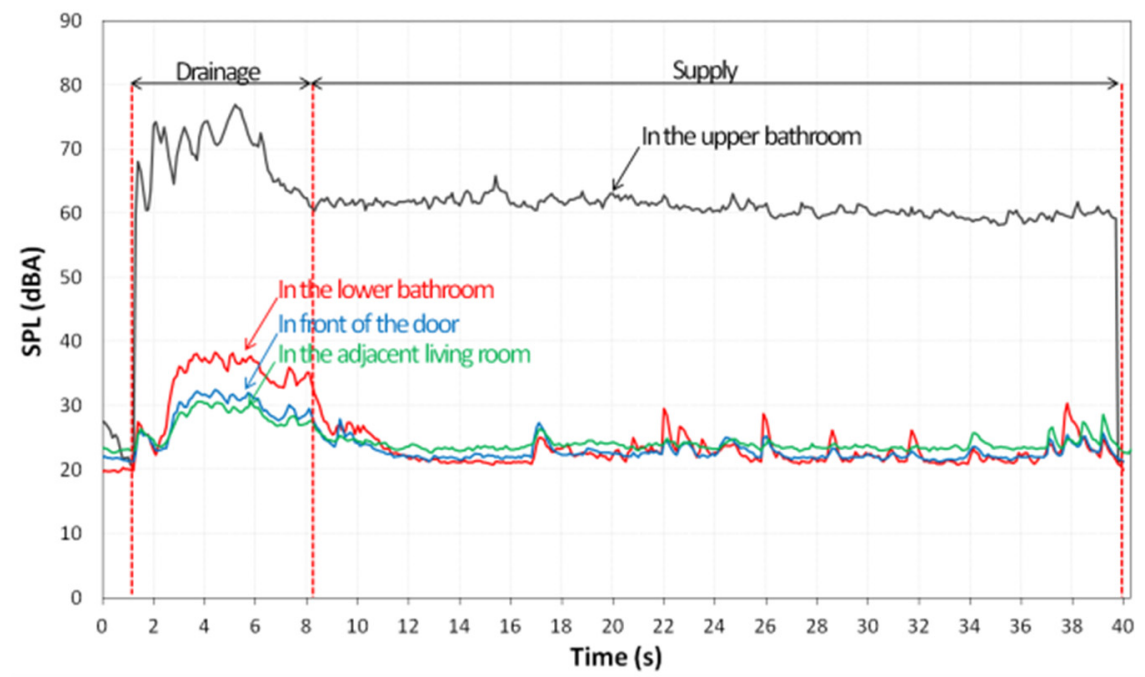

(a)

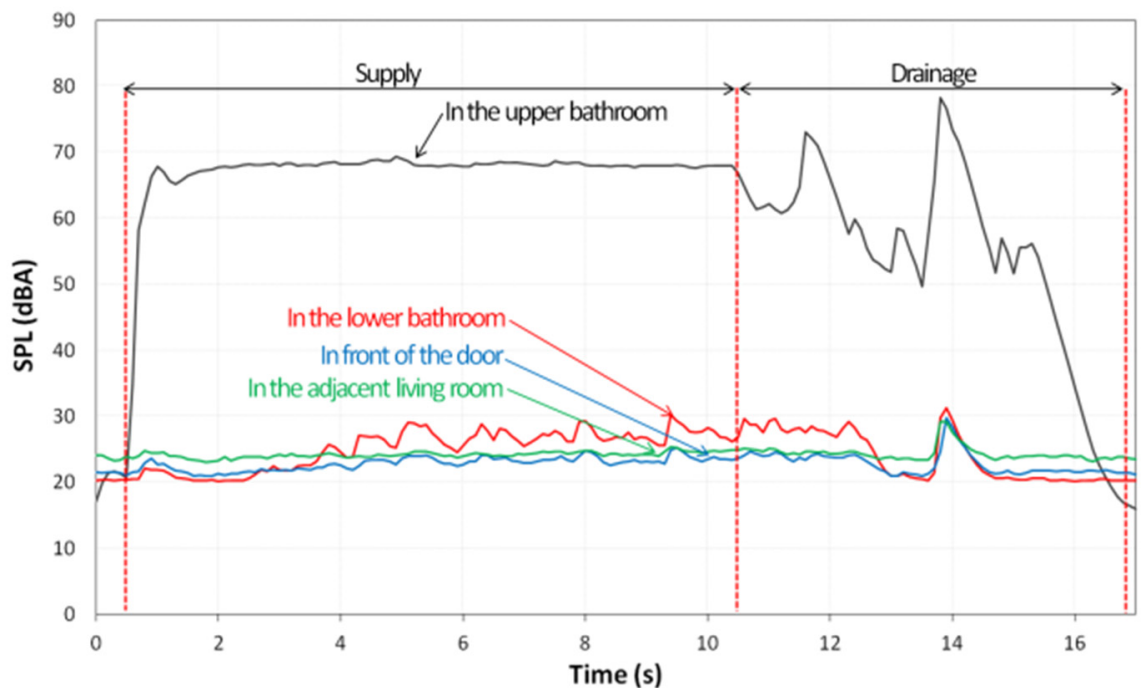

(b)

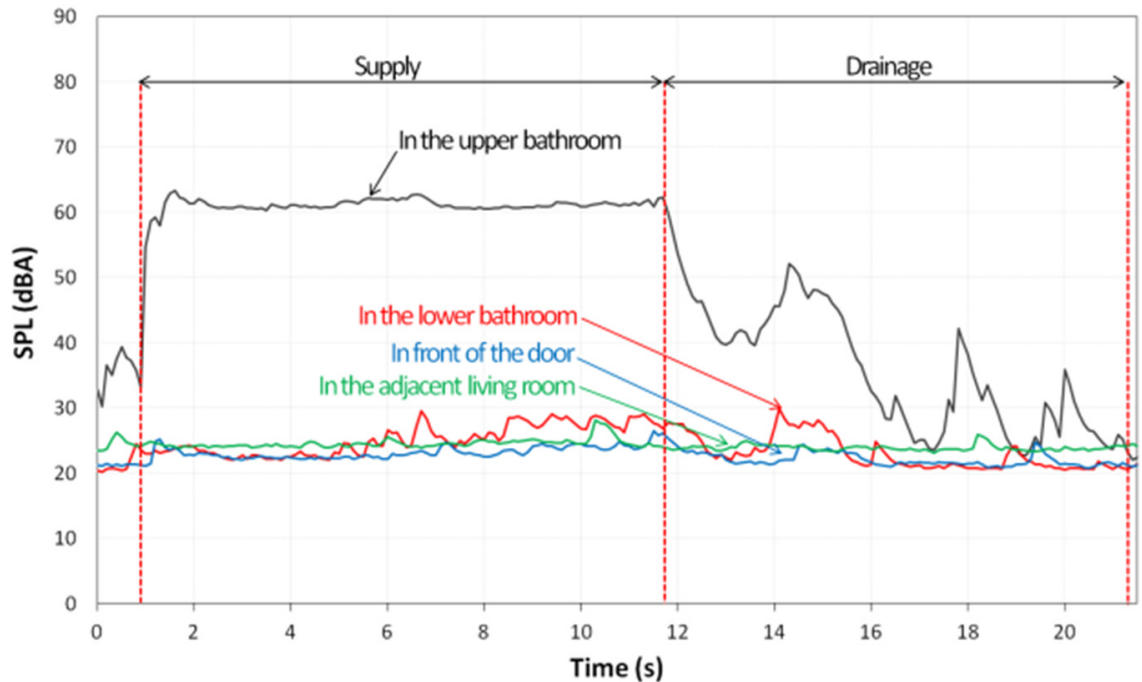

(c)

Figure 5. Time history of water supply and drainage noises from the use of sanitary wares including the (a) water closet, (b) basin, and (c) bathtub measured at different locations (only a part of the time history has been shown due to long-time operation). 


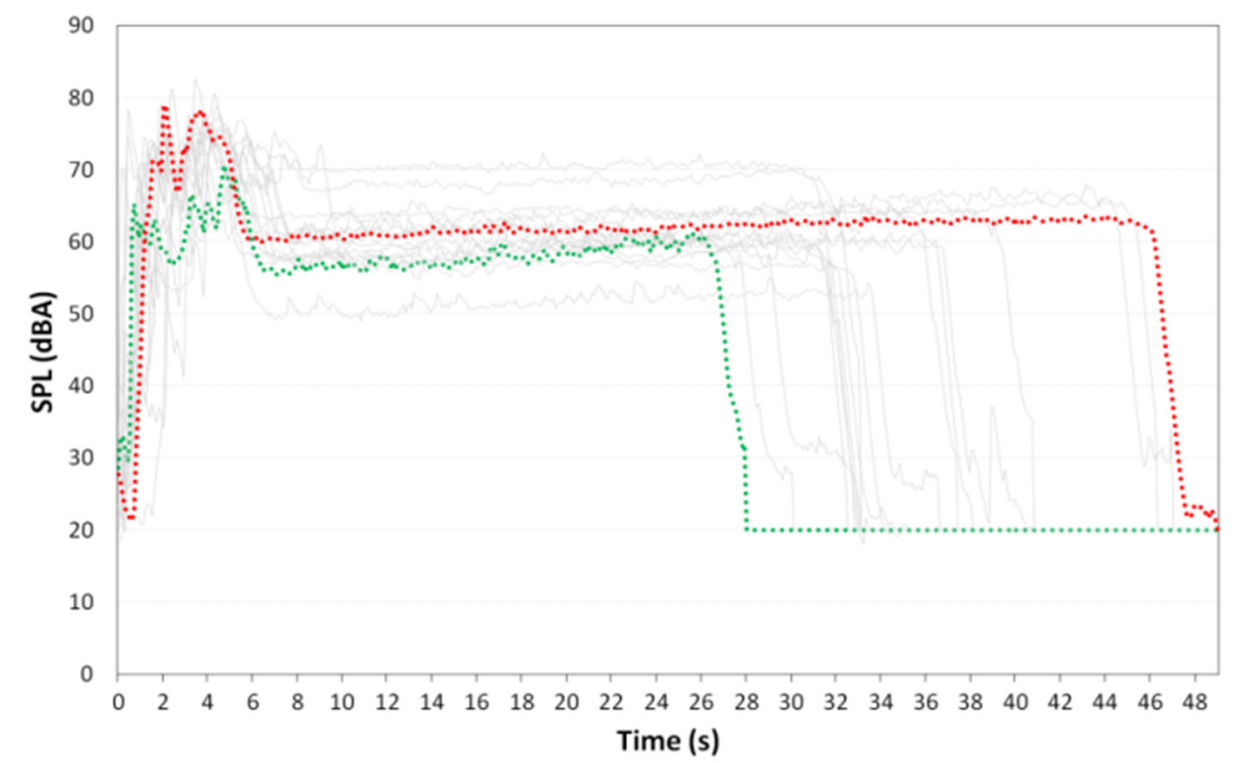

Figure 6. Time history of the noise from the use of the water closet installed in 19 bathrooms of 11 housings with different floor plans (longest time with red dot: bathroom attached to the living room of the 59A type; shortest time with green dot: bathroom attached to the bedroom of the 84A type).

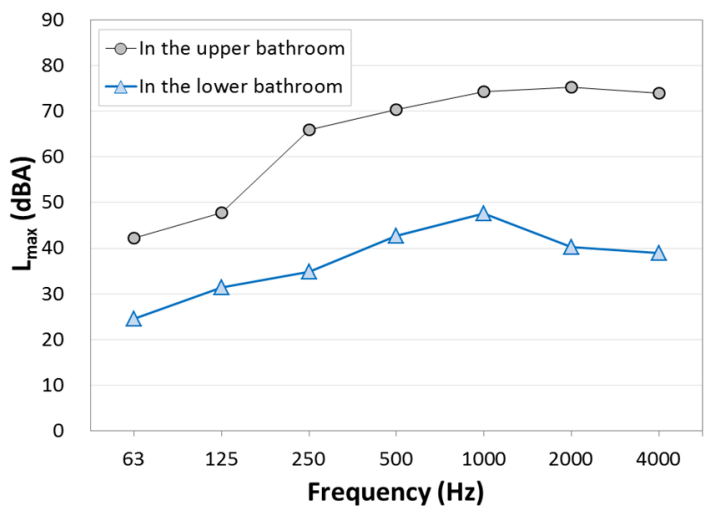

(a)

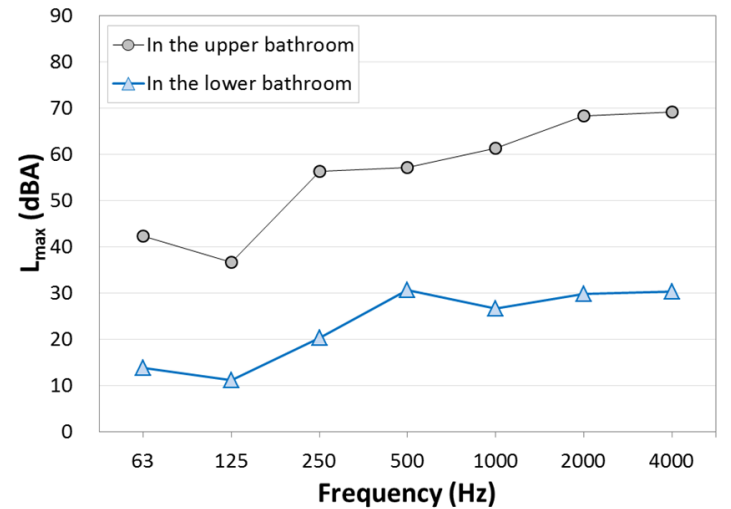

(b)

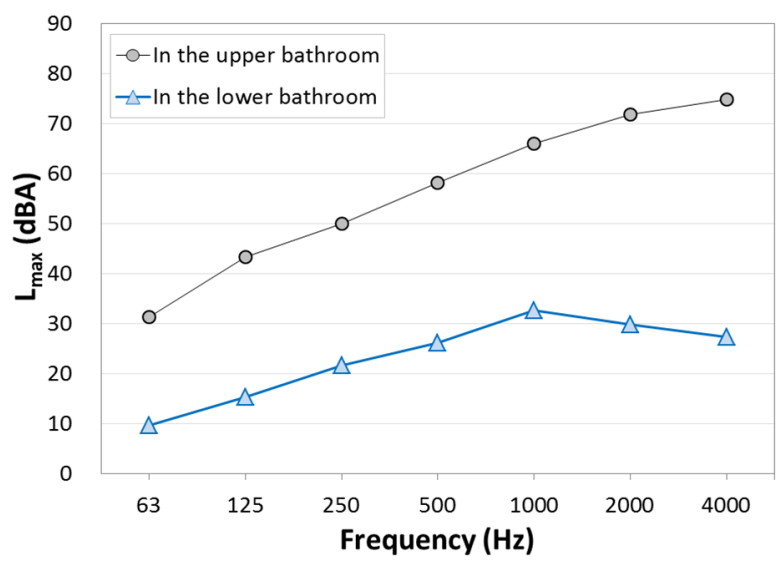

(c)

Figure 7. Frequency spectrum of the water supply and drainage noises ( $\left.\mathrm{L}_{\mathrm{AFmax}}\right)$ from the use of the sanitary wares in the bathrooms attached to the living room of the upper and lower floors for the 59A type: (a) water closet; (b) basin; (c) bathtub. 
Figure 8 shows the average noise level from the use of each sanitary ware measured in the bathrooms of the lower floor attached to the living room $(N=64)$ and bedroom $(N=49)$. The results show that the highest noise level is $47.8 \mathrm{dBA}$ for the water drainage from the use of the water closet in the bathroom attached to the bedroom. The noise level of the second ranking is $42.7 \mathrm{dBA}$ for the water drainage from the use of the basin in the bathroom attached to the bedroom. The water supply noise shows similar levels approximately between $33.7 \mathrm{dBA}$ and $37.0 \mathrm{dBA}$ for all of the sanitary wares. The deviation bar indicating the range between the maximum and minimum noise levels implies that the noise level is different according to the studied housings with different plans.

The graph in Figure 9 shows the frequency distribution and cumulative percentage of the maximum noise level in 113 bathrooms of the lower floor according to the water supply and drainage noises of the three sanitary wares. It can be seen that the maximum noise level is concentrated between $46 \mathrm{dBA}$ and $50 \mathrm{dBA}$. The lowest value of the maximum noise level is $41.3 \mathrm{dBA}$, whereas the highest value is $60.1 \mathrm{dBA}$. The average value of the maximum noise levels measured in the 113 bathrooms is $47.7 \mathrm{dBA}$. The results indicate that most of the residents living in the lower floor can recognize the noise in the bathroom due to the use of the sanitary wares in the upper floor because the $\mathrm{S} / \mathrm{N}$ ratio is approximately $30 \mathrm{dBA}$ if the background-noise level is assumed to be $20 \mathrm{dBA}$.

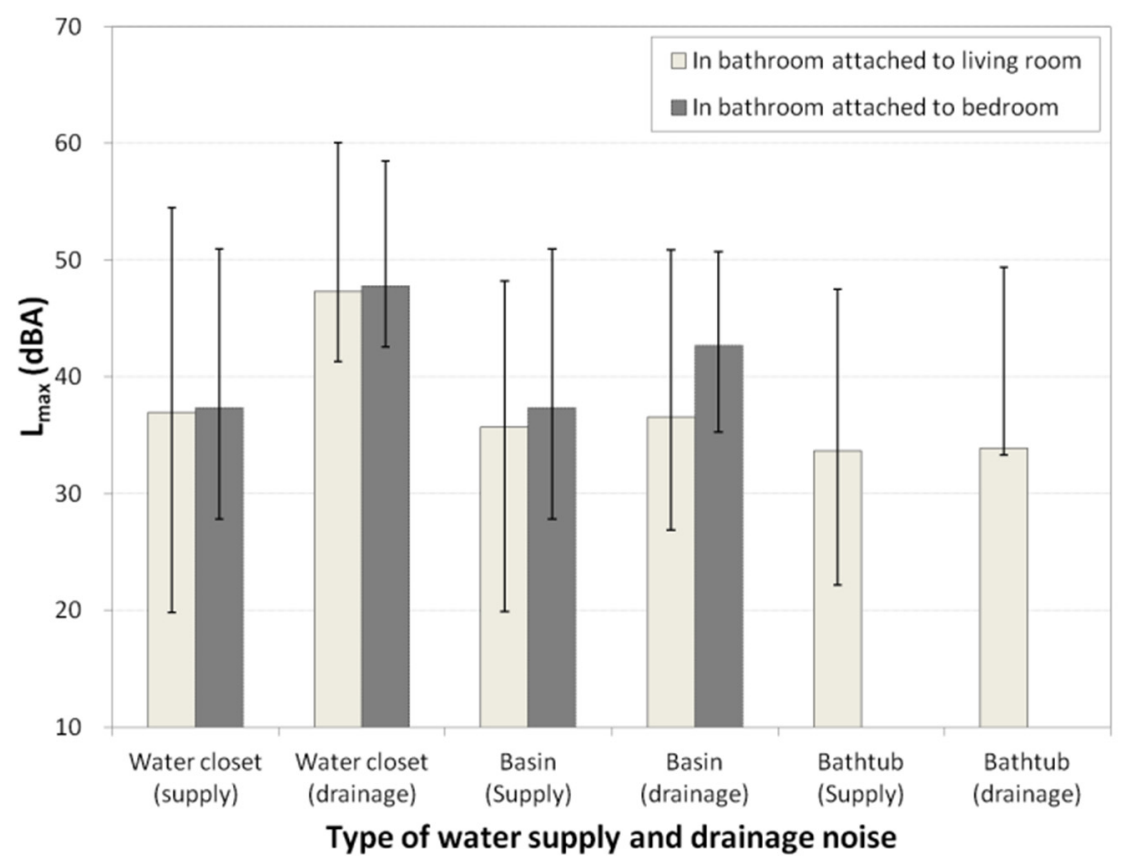

Figure 8. Average noise level for each sanitary ware measured in the bathrooms of the lower floor attached to the living room $(N=64)$ and bedroom $(N=49)$. The deviation bar indicates the range between the maximum and minimum noise levels measured in the different bathrooms.

One of the major factors determining the noise level could be the construction method of the bathroom. In this study, the UBR system has been applied to the floor plans with a small floor area less than $46 \mathrm{~m}^{2}$, while the wet-construction method was applied for the larger floor plans. Figure 10 shows the average noise level for the water supply and drainage of each sanitary ware according to the construction methods, including the UBR system $(N=15)$ and the wet-construction method $(N=97)$. The results in Figure 10 indicate that the UBR system generates a noise level that is lower than that of the wet-construction method for all of the operational conditions of each sanitary ware. The highest value of the noise level for the UBR system is $42.8 \mathrm{dBA}$ for the water drainage of the water closet, while it is $48.2 \mathrm{dBA}$ for the wet-construction method. It is also noted that the UBR system has a rather low deviation between the maximum and minimum noise levels compared with the wet-construction 
method. This implies that the UBR system is advantageous for the management of construction quality in terms of sound insulation.

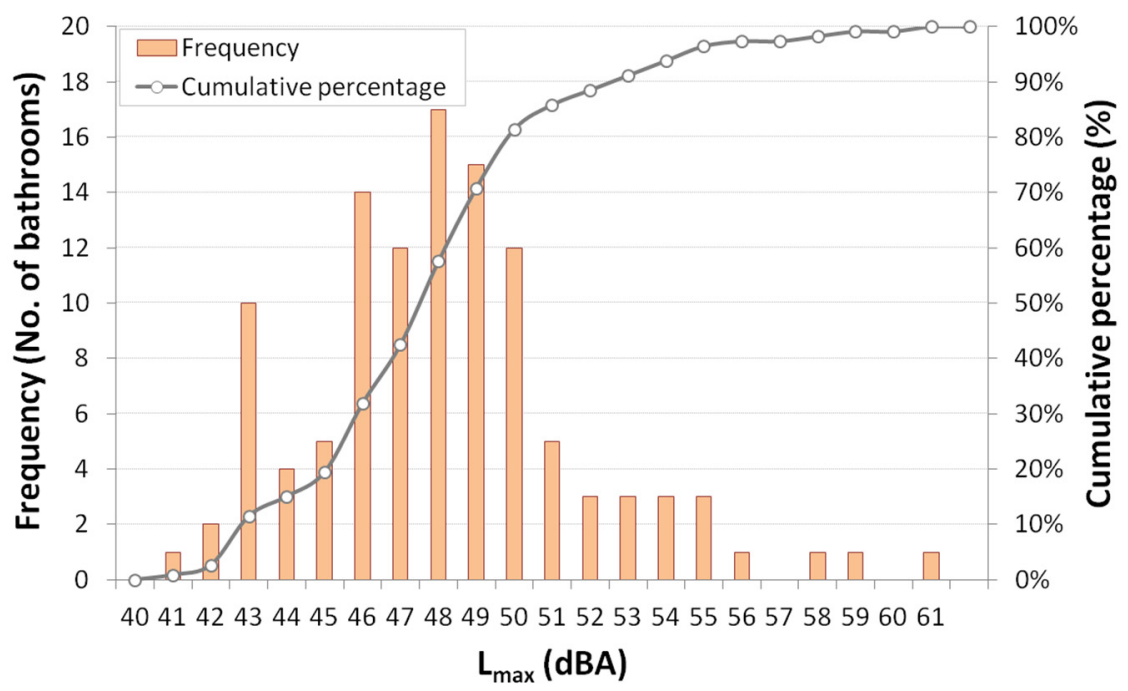

Figure 9. Frequency distribution and cumulative percentages of water supply and drainage noises $\left(\mathrm{L}_{\mathrm{AFmax}}\right)$ in the bathrooms of the lower floor from the use of the sanitary wares $(N=113)$.

In multi-residential buildings, the noise level could change due to the different altitudes of the properties in the multi-residential buildings, thereby affecting the water supply pressure and drainage velocity. The influence of the altitude on the variation of the noise level was therefore examined by dividing the total floors as groups of low (10 floors or fewer, $N=60$ ) and high (11 floors or more, $N=53$ ) floors, as shown in Figure 11. The results show that the noise levels measured at the low and high floors are similar to each other for all of the operational conditions. This indicates that the altitude of the housing is a manageable design factor affecting the variation of the noise level.

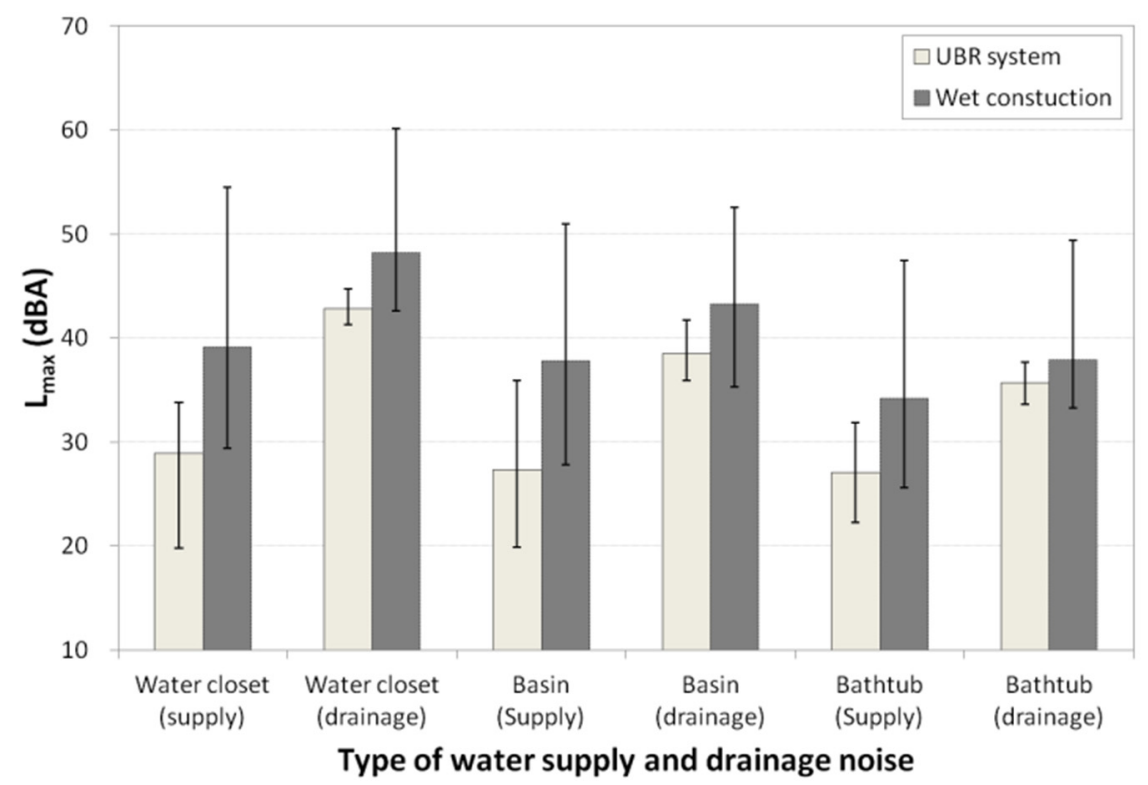

Figure 10. Average noise level for each sanitary ware according to the construction methods including the UBR system $(N=15)$ and wet-construction method $(N=97)$. The deviation bar indicates the range between the maximum and minimum noise levels measured in the different bathrooms. 


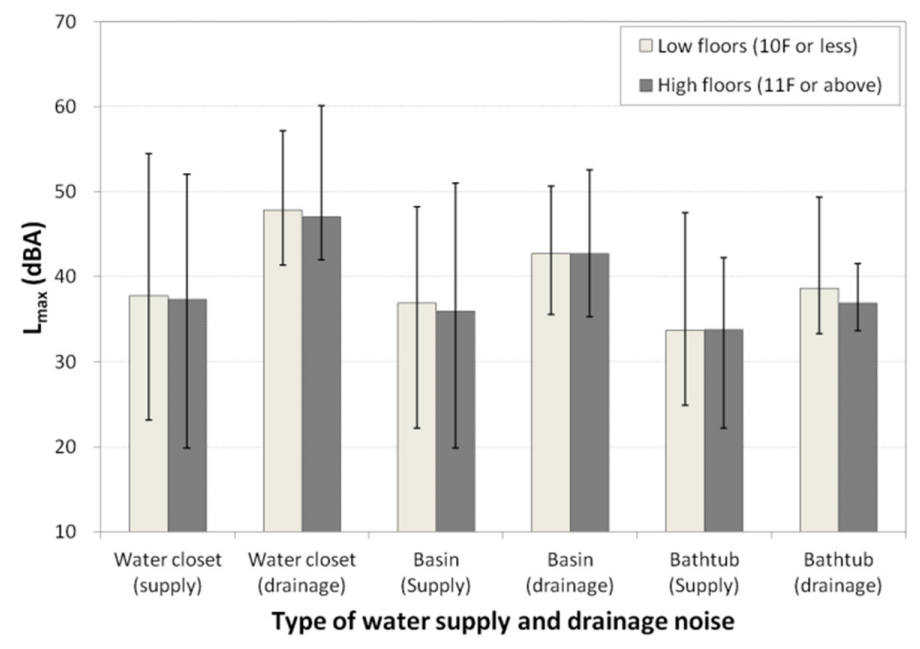

Figure 11. Water supply and drainage noises $\left(\mathrm{L}_{\mathrm{AFmax}}\right)$ according to the groups of low $(N=60)$ and high $(N=53)$ floors.

\subsection{Noise Level in the Adjacent Room}

The noise levels in the living room and bedroom due to the water supply and drainage in the bathroom form one of the important criteria affecting the indoor environmental quality of multi-residential buildings. Figure 12 shows an example of the frequency spectrum for the water supply and drainage noises from the use of the water closet measured in different locations including the bathroom, in front of the door, and in the adjacent room of the lower floor for the 59B type; here, the door of the bathroom was closed. The results show that the noise levels in both of the adjacent rooms decreased by approximately $10 \mathrm{dBA}$ at the middle frequencies compared with those in the bathroom, while those in front of the door and in the adjacent rooms are similar. It is noted that the overall noise levels in both rooms are strongly determined at $500 \mathrm{~Hz}$ and $1000 \mathrm{~Hz}$.

Figure 13 is a graph showing the noise levels measured in the living room $(N=11)$ and bedroom $(N=8)$ of 11 different floor plans according to the different operational conditions of each sanitary ware. The sanitary ware generating the highest noise level is the drainage noise from the water closet for both rooms. The average noise level for the water drainage from the water closet in the bedroom is $39.1 \mathrm{dBA}$, while it is $34.3 \mathrm{dBA}$ in the living room. Generally, the noise level in front of the door is slightly higher than those in the adjacent rooms.

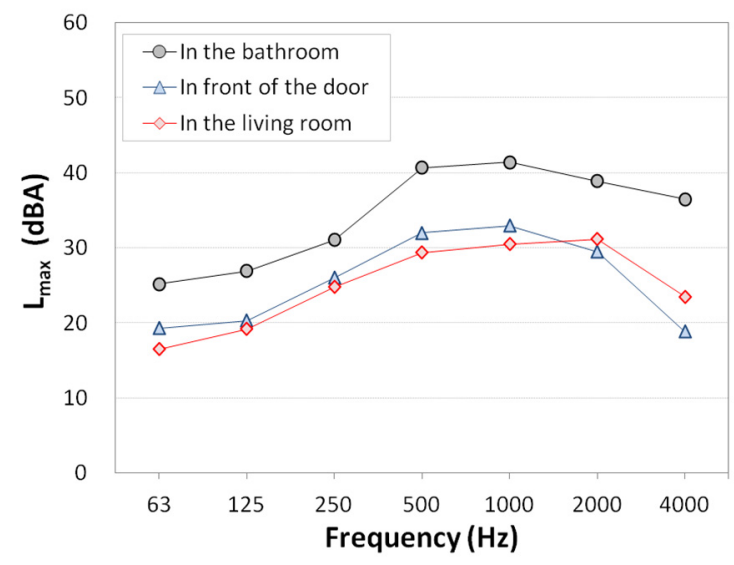

(a)

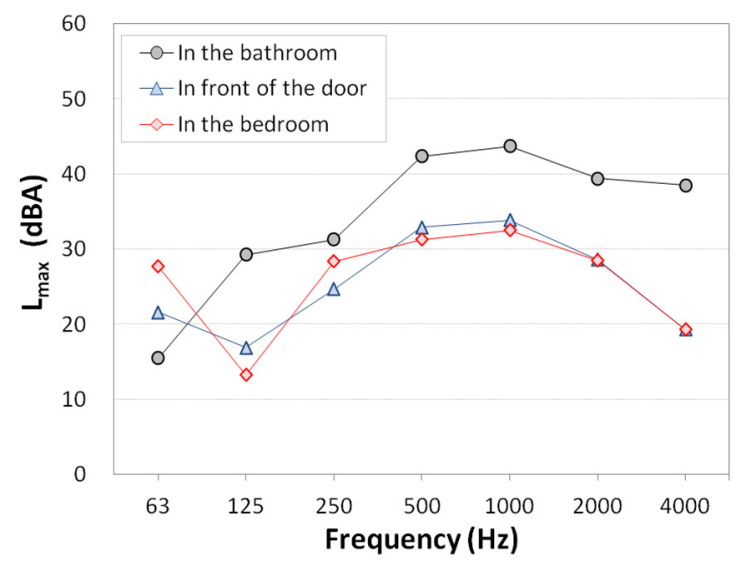

(b)

Figure 12. Frequency spectrum of water supply and drainage noises from the use of the water closet measured in the (a) living room and (b) bedroom of the lower floor for the 59B type. 


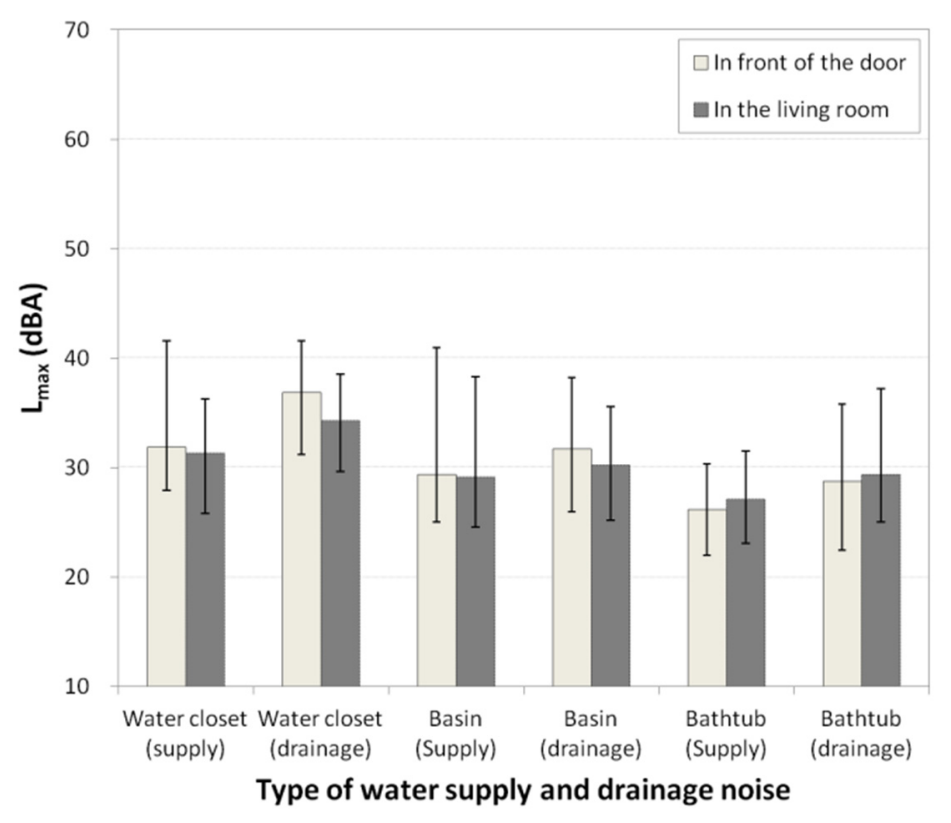

(a)

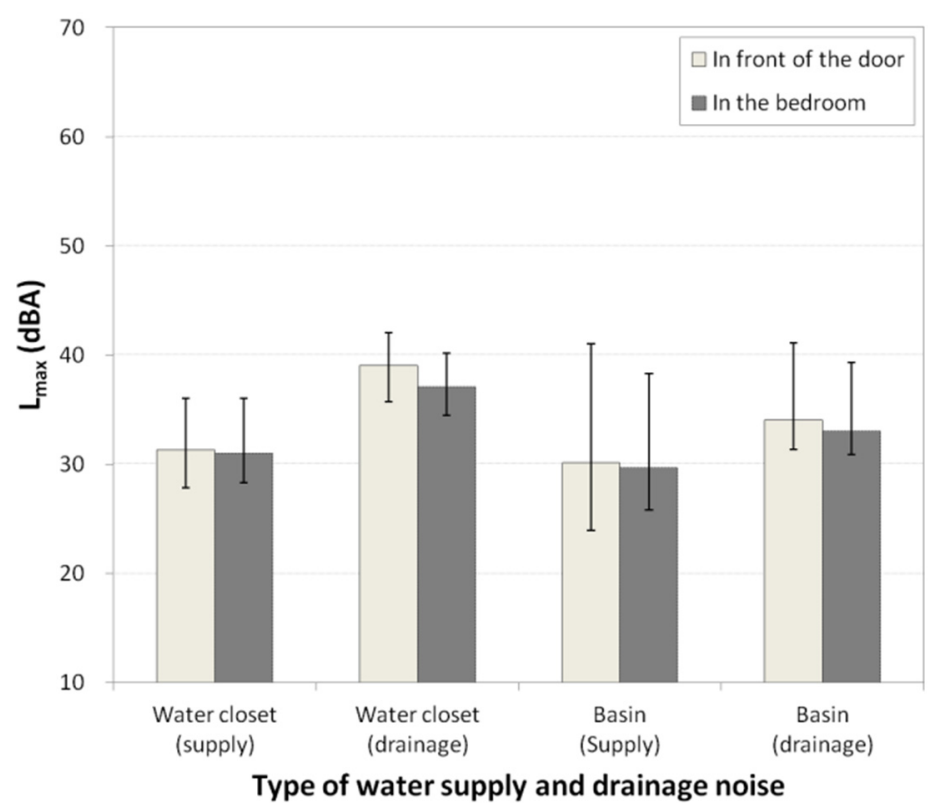

(b)

Figure 13. Noise levels measured in the living room $(N=11)$ and bedroom $(N=8)$ according to the different operational conditions of each sanitary ware in 11 different floor plans: (a) living room; (b) bedroom.

Figure 14 shows the frequency distribution and cumulative percentages of the maximum noise levels in the living room and bedroom of the lower floor according to the water supply and drainage noises of the three sanitary wares. The results show that the noise level is concentrated at about $37 \mathrm{dBA}$, which leads to an average noise level of $37.8 \mathrm{dBA}$. This result indicates that the water supply and drainage noises could be noticeable, especially at night-time when the background noise is low. Based on the 2nd ISO/CD 19488, it is expected that the average noise level in the rooms meets Class C (living room) and Class D (bedroom) if the RT is normalized. 


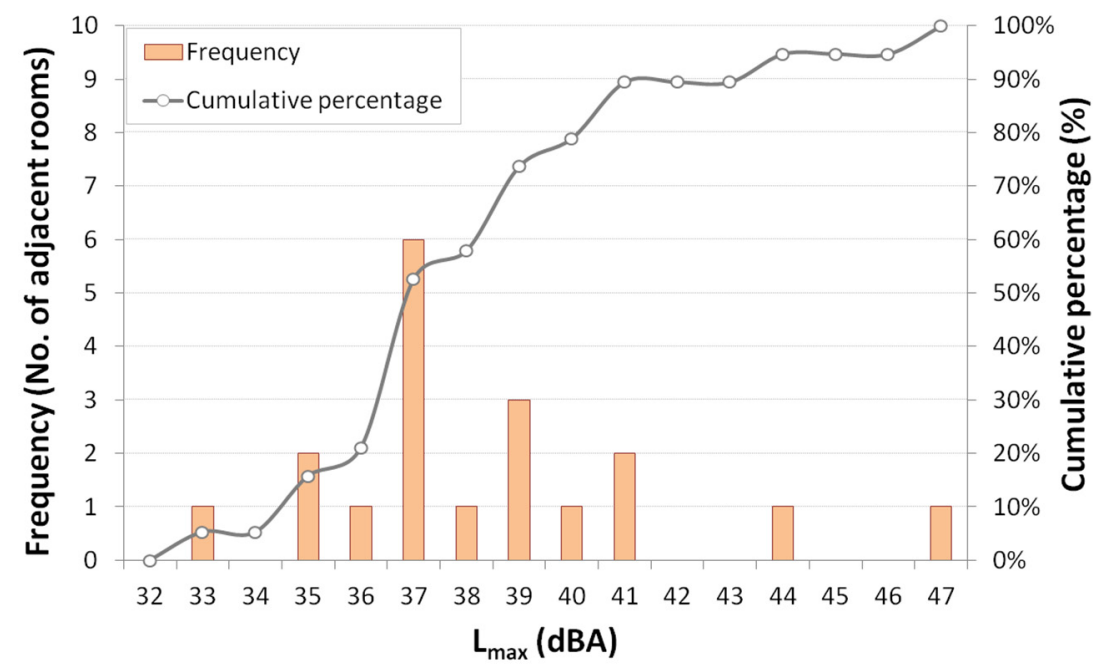

Figure 14. Frequency distribution and cumulative percentages of water supply and drainage noises ( $\left.\mathrm{L}_{\mathrm{AFmax}}\right)$ in the living room $(N=11)$ and bedroom $(N=8)$ of the lower floor from the use of the sanitary wares.

\section{Discussion}

Although the focus of this study is the noise levels in situ due to the sanitary wares in the bathroom and adjacent rooms, the final goal of this study is a practical guideline suggestion regarding a way that the noise and vibration transmitted from the bathroom to the adjacent rooms can be controlled to satisfy each class limit described in the 2nd ISO/CD 19488 or the national regulation. Based on the data measured in this study, additional measurements for vibration and sound intensity will be carried out to examine the contribution of the sound energies transmitted through the floor, ceiling, wall, door, and leakages. A laboratory-based experiment is also needed to discover the noise-reduction design factors including the air cavity between the ceiling and floor, the absorber, the sound insulation of the PVC panels covering the ceiling, the vibration isolation of the pipe, the amount of used water, the water pressure, and the lengths and tilting angles of the pipes. Although EN 12354-5 [17] suggests a prediction method of sound levels due to the service equipment, a developed prediction method will also need to be suggested considering the Korean situation. Moreover, a prediction of the sound propagation from the bathroom to the adjacent rooms needs to be carried out in consideration of the various design factors such as the existence of a dressing room, the location of the bathroom, and the distance between the bathroom and the living room.

\section{Conclusions}

In this study, a series of field measurements were carried out to examine the current situation regarding the water supply and drainage noise in the bathrooms of the multi-residential buildings of Korea. The number of studied housings is 64 , and they comprise 14 different floor plans. The water supply and drainage noise were measured in the bathrooms of the lower floor according to the different operations of each sanitary ware including the water closet, basin, and bathtub. The noise levels were also measured in the bathrooms of the upper floor and the adjacent rooms of the lower floor for 11 housing units with different floor plans. The measurement parameters in this study are therefore as follows: (1) noise level in the bathroom of the lower floor $(N=113)$; (2) noise level in the bathroom of the upper floor $(N=19)$; and (3) noise levels in the living room $(N=11)$ and bedroom $(N=8)$ of the lower floor. The time history of the measured SPL from the use of each sanitary ware displayed strongly fluctuating noise levels for the water drainage, while it is rather continuous for the water supply. Also, the water supply and drainage noises produce relatively high SPL values at $500 \mathrm{~Hz}$ and $1000 \mathrm{~Hz}$, respectively, compared with the other frequencies. 
The measurement results in the bathrooms of the lower floor $(N=113)$ showed that the highest noise level is $47.8 \mathrm{dBA}$ on average for the water drainage noise from the use of the water closet. The second ranking comprises $42.7 \mathrm{dBA}$ for the water drainage noise from the use of the basin, and then $33.9 \mathrm{dBA}$ was measured for the water drainage noise from the use of the bathtub. The water supply noise ranged between $33.7 \mathrm{dBA}$ and $37.0 \mathrm{dBA}$. The above results suggest that the priority for noise control is in the order of water drainage from the water closet, water drainage from the basin, and water supply to the sanitary wares, as well as water drainage from the bathtub. The frequency distribution and cumulative percentages of the water supply and drainage noises in the bathrooms of the lower floor suggested that the maximum noise level is concentrated between $46 \mathrm{dBA}$ and $50 \mathrm{dBA}$, thereby deriving the average noise level of $47.7 \mathrm{dBA}$. The minimum and maximum noise levels ranged between $41.3 \mathrm{dBA}$ and $60.1 \mathrm{dBA}$. According to the different construction methods of the bathrooms, the UBR system produced a noise level that is lower than that of the wet-construction method for all of the operational conditions of each sanitary ware. The highest noise level for the UBR system is $42.8 \mathrm{dBA}$, while it is $48.2 \mathrm{dBA}$ for the wet-construction method. The altitude of the housing has an insignificant influence on the variation of the noise level.

The highest noise levels in the living room $(N=11)$ and bedroom $(N=8)$ of the lower floor are $34.3 \mathrm{dBA}$ and $39.1 \mathrm{dBA}$, respectively, for the water drainage noise from the use of the water closet. The frequency distribution and cumulative percentages of the maximum noise level in the adjacent rooms was concentrated at approximately $37 \mathrm{dBA}$, thereby deriving the average noise level of $37.8 \mathrm{dBA}$.

The overall results suggest that the current situation of water supply and drainage noise in the multi-residential buildings of Korea meets Class C (living room) and Class D (bedroom) of the 2nd ISO/CD 19488, although some of the measurement data from the rooms are outside of the minimum limit; however, it is still necessary to develop the acoustic guidelines to satisfy the higher class for the creation of a comfortable residential environment.

Acknowledgments: This work was supported by the 2016 Research Fund of Korea Land and Housing Corporation (R201605003).

Author Contributions: Hong-Seok Yang conceived and designed the experiments; Hong-Seok Yang and Hyun-Min Cho performed the experiments; Hong-Seok Yang and Myung-Jun Kim analyzed the data; and Hong-Seok Yang wrote the paper.

Conflicts of Interest: The authors declare no conflicts of interest.

\section{References}

1. G-SEED Green Standard for Energy and Environmental Design. Available online: http://www.g-seed.or.kr/ english (accessed on 19 September 2016).

2. Fuchs, H.V. Generation and control of noise in water supply installations: Part 1: Fundamental aspects. Appl. Acoust. 1983, 16, 325-346. [CrossRef]

3. Fuchs, H.F. Generation and control of noise in water supply installations. Part 2: Sound source mechanisms. Appl. Acoust. 1993, 38, 59-85. [CrossRef]

4. Fuchs, H.V. Generation and control of noise in water supply installations Part 3: Rating and abating procedures. Appl. Acoust. 1993, 39, 165-190. [CrossRef]

5. Prek, M. The impact of geometrical parameters on hydrodynamic noise generation. Appl. Acoust. 2000, 60, 343-351. [CrossRef]

6. Korea Standard (KS). KS F 2870:2006. Field Measurements of Water Supply Noise in Apartment Bathroom; Korea Standard (KS): Seoul, Korea, 2006.

7. Korea Standard (KS). KS F 2871:2006. Field Measurements of Drainage Noise in Apartment Bathroom; Korea Standard (KS): Seoul, Korea, 2006.

8. The Ministry of Land Infrastructure and Transport. Criteria for the Interlayer Floor Impact Sound Regulation in Multi-Residential Buildings; Notification on 2014-446; The Ministry of Land Infrastructure and Transport: Sejong-si, Korea, 2014.

9. The Ministry of Land Infrastructure and Transport. Sound Insulation of the Wall Structure and Management Regulation; Notification on 2015-844; The Ministry of Land Infrastructure and Transport: Sejong-si, Korea, 2015. 
10. The Ministry of Land Infrastructure and Transport. Regulations on Housing Construction Standards; Notification on 2014; The Ministry of Land Infrastructure and Transport: Sejong-si, Korea, 2014.

11. Korea Standard (KS). KS F 2872:2008. Rating of Water Supply Noise in Apartment Bathroom; Korea Standard (KS): Seoul, Korea, 2008.

12. International Organization for Standardization. ISO/2ndCD 19488:2016. Acoustics—Acoustic Classification of Dwellings; International Organization for Standardization: Geneva, Switzerland, 2016.

13. International Organization for Standardization. ISO 16032:2014. Measurement of Sound Pressure Level from Service Equipment in Buildings-Engineering Method; International Organization for Standardization: Geneva, Switzerland, 2014.

14. International Organization for Standardization. ISO 10052:2004. Field Measurements of Airborne and Impact Sound Insulation and of Service Equipment Sound-Survey Method; International Organization for Standardization: Geneva, Switzerland, 2004.

15. American Society of Heating, Refrigerating and Air-Conditioning Engineers, Inc. Chapter 48. Noise and vibration. In ASHRAE Handbook; American Society of Heating, Refrigerating and Air-Conditioning Engineers, Inc.: Atlanta, GA, USA, 2011.

16. Kim, M.J.; Lee, B.K. Field measurement and evaluation of the reverberation time in residential buildings. J. Korean Soc. Living. Environ. Syst. 2006, 13, 213-221.

17. BSI Group. EN 12354-5:2009. Building Acoustics-Estimation of Acoustic Performance of Building from the Performance of Elements_Part 5: Sounds Levels Due to the Service Equipment; BSI Group: London, UK, 2009.

(C) 2016 by the authors; licensee MDPI, Basel, Switzerland. This article is an open access article distributed under the terms and conditions of the Creative Commons Attribution (CC-BY) license (http:/ / creativecommons.org/licenses/by/4.0/). 